\title{
SALTOVO-MAYAKI PROVINCIAL BYZANTINE CULTURE OF THE CRIMEA
}

\author{
Vadim V. Maiko \\ Institute of Archaeology of Crimea, RAS, Simferopol, Russian Federation
}

\begin{abstract}
Introduction. The material culture of Byzantium throughout the entire period of existence of the empire consisted of a number of the provincial Byzantine cultures. This is also true for material cultures of border territories of Byzantium which could not be a part of the state, but were exposed to the Byzantine cultural and economic influence. Taurika acted as such territories in the $8^{\text {th }}-9^{\text {th }}$ centuries. During this period the Crimean option of Saltovo-Mayaki archaeological culture was widespread in its east, central and northwest part. The question of legitimacy of reference of this culture to the provincial Byzantine is the research task.

Methods. On the basis of a comparative method, the attempt to consider those aspects of Saltovo-Mayaki culture of the Crimea which allow carrying it to the provincial Byzantine is made. The archaeological material which is saved up so far acts as sources of research which allow considering a debatable problem of essence of SaltovoMayaki culture of the peninsula in the modern historiography.

Analysis. Almost all parties of the considered culture allow comparing it with the provincial Byzantine cultures of the Alano-Gothic population of Taurika.

Results. As a result of the conducted research, the Saltovo-Mayaki culture of Taurika can be considered as one of options of the provincial Byzantine culture. It was left not by the Greek population which constantly had the Byzantine influence in the field of ideology and life. The provincial Byzantine nature of this material culture is not an argument for judgments of political dependence of territories where it was widespread.

Key words: Byzantium, Taurika, Saltovo-Mayaky culture, Byzantine features, ethnos.

Citation. Maiko V.V. Saltovo-Mayaki Provincial Byzantine Culture of the Crimea. Vestnik Volgogradskogo gosudarstvennogo universiteta. Seriya 4, Istoriya. Regionovedenie. Mezhdunarodnye otnosheniya [Science Journal of Volgograd State University. History. Area Studies. International Relations], 2018, vol. 23, no. 5, pp. 79-87. (in Russian). DOI: https://doi.org/10.15688/jvolsu4.2018.5.7
\end{abstract}

УДК 904 (470)“08/09”

Дата поступления статьи: 01.07.2018

ББК 63.4(2)

Дата принятия статьи: 05.09.2018

\section{САЛТОВО-МАЯЦКАЯ ПРОВИНЦИАЛЬНО-ВИЗАНТИЙСКАЯ КУЛЬТУРА КРЫМА}

\author{
Вадим Владиславович Майко \\ Институт археологии Крыма РАН, г. Симферополь, Российская Федерация
}

\begin{abstract}
Аннотация. Материальная культура Византия в течение всего периода существования империи состояла из разнообразных провинциально-византийских культур. Сказанное справедливо и для материальных культур пограничных территорий Византийского государства, в том числе и Таврики VIII в. - рубежа IX$\mathrm{X}$ веков. В тот период в восточной, центральной и северо-западной части полуострова был распространен так называемый крымский вариант салтово-маяцкой археологической культуры. Обоснование правомерно$\infty$ сти отнесения этой культуры к провинциально-византийской является целью работы.

Накопленный к настоящему времени обширный археологический материал, связанный с рассматриваемой культурой, позволяет по-новому рассмотреть спорный в современной историографии вопрос соотнесения ее с провинциально-византийской и прежде всего культурой гото-аланского населения средневековой Таврики.

В результате проведенного сравнительного анализа салтово-маяцкую культуру Крыма можно считать одним из вариантов провинциально-византийской культуры. Оставлена она была негреческим населением,
\end{abstract}


которое постоянно испытывало византийское влияние в области идеологии и быта. Важно подчеркнуть, что отнесение этой культуры к провинциально-византийской не является аргументом в пользу суждений о политической зависимости территорий, где она была распространена.

Ключевые слова: Византия, Таврика, салтово-маяцкая культура, византийские черты, этнос.

Цитирование. Майко В. В. Салтово-маяцкая провинциально-византийская культура Крыма // Вестник Волгоградского государственного университета. Серия 4, История. Регионоведение. Международные отношения. - 2018. - Т. 23, № 5. - C. 79-87. - DOI: https://doi.org/10.15688/jvolsu4.2018.5.7

Введение. Археологическое наполнение термина «провинциально-византийская культура» - одна из важнейших задач археологоввизантинистов. Вместе с тем это необходимое условие, чтобы сделать выводы об этническом составе жителей византийских провинций. Сказанное совершенно справедливо и по отношению к средневековому Крыму. В данном случае имеется в виду та территория полуострова, которая в VIII в. - на рубеже IX$\mathrm{X}$ вв. была занята населением, оставившим так называемый крымский вариант салтовомаяцкой археологической культуры.

В последнее время проблема ее этнокультурной атрибуции вновь стала предметом острых дискуссий $[11 ; 17 ; 32]$. То, что считалось в свое время достижением отечественной археологии (выделение крымского варианта салтово-маяцкой культуры), сейчас, на фоне критики самого термина «салтово-маяцкая культура» Крыма [33, с. 140-172], подвергается все большему сомнению. Для продвижения вперед необходимо определиться с термином «провинциально-византийская культура» и признать отсутствие в нем какоголибо этнического и тем более политического определения. Именно при таком подходе перспективно рассматривать сущность салтовомаяцкой культуры полуострова.

Методы. Источниками для решения поставленных целей является огромный массив археологического материала, полученного за более чем 50 лет целенаправленных раскопок салтово-маяцких памятников полуострова. Этот материал, правда в меньшем объеме, был доступен и нашим предшественникам. Основные концепции относительно рассматриваемой археологической культуры в настоящее время сводятся к двум основным точкам зрения. Согласно первой, преобладающей, она является вариантом салтово-маяцкой археологической культуры, не имеющей отношения к провинциально-византийской и ос- тавленной тюрко-болгарским этносом, находившимся в политической зависимости от Хазарии. Вторая точка зрения рассматривает ее в качестве варианта провинциально-византийской культуры полуострова, оставленной ромейским этносом на территории имперских владений в Таврике.

Анализ. Попытаемся разрешить это надуманное противоречие путем проведения простого сравнительного анализа основных составляющих салтово-маяцкой культуры Крыма по степени присутствия черт, фиксируемых в Константинополе и центральных провинциях Византийской империи.

Жилая и хозяйственная застройка представлена домами двух основных типов. Первый представляют постройки на каменных цоколях, встреченные в основном на многочисленных сельских поселениях [27]. Второй аналогичные по конструкции сооружения, но стены которых сложены из камня на всю высоту [6]. Зафиксированы они преимущественно в городских центрах. Каменные дома неоднократно рассматривались в литературе [3, с. 48-53; 4; 13]: проанализированы их конструктивные особенности, разработана типология, предложено хронологическое членение. В настоящее время выделяется 8 типов жилых сооружений, среди которых можно отметить однокамерные и двухкамерные дома с округлой в плане пристройкой и многокамерные дома со смежными помещениями [27]. Отмечается и наличие подобных вариантов построек с хозяйственной пристройкой [30]. Удалось обнаружить общие и индивидуальные черты, присущие наиболее распространенному типу салтово-маяцких сооружений - домупятистенке [29].

При рассмотрении данного аспекта важно следующее. Время появления каменных домов на разных памятниках было различным и зависело от целого ряда объективных и субъективных причин. В городах оно шло 
быстрее и революционнее [5], на периферии медленнее [27]. Как показывают раскопки Сугдеи, наиболее ранние каменные двухкамерные дома на территории городища датируются первой половиной VIII в. [5]. В то же время каменные дома, расположенные на посаде этого средневекового города, возникают не ранее середины IX века. Совершенно очевидно, что, несмотря на эволюционный характер, появление каменных домов, особенно в городах, явилось результатом заимствований приемов византийского домостроительства и организации жилого пространства.

Тем не менее одновременно с каменными домами, по крайней мере до середины IX в., на площади практически всех исследованных салтово-маяцких поселений существовали и полуземлянки. Время их возведения и прекращения функционирования в большинстве случаев установить достаточно сложно. Причины здесь разные, но не связанные с какими-либо политическими конфликтами или этническими процессами. Таким образом, жилая и хозяйственная застройка, сама предельно простая организация жилого и хозяйственного пространства внутри жилища имеют несомненные византийские черты, связанные с использованием передовых технологий, творчески переработанных с учетом существовавших традиций. В качестве последних можно рассматривать технику кладки «в елку» и наличие полуземлянок, придающих жилищному и хозяйственному строительству и планировке поселений определенную специфику. Необходимо учитывать и то, что переход к каменному строительству был связан прежде всего с процессом оседания населения на землю.

Спорным моментом являются время возведения и характер фортификационных сооружений, зафиксированных в Сугдее и на Боспоре [10]. Не исключено, что инженерами в данном случае выступали византийские мастера. Однако стены возводились и ремонтировались местным населением, о чем красноречиво свидетельствуют разнообразные тамгообразные знаки, обнаруженные, в частности, на каменных крепостных блоках Сугдеи [13, с. 234-244]. Они аналогичны экземплярам Маяцкого городища и городов Болгарии. Вместе с тем принципы построения кре- постных сооружений Сугдеи уходят корнями в византийскую фортификацию, но окончательно она становится таковой только во второй половине X века.

Погребальный обряд населения ЮгоВосточного Крыма в рассматриваемый хронологический период также изучен относительно неплохо [3, с. 105-129; 13, с. 119-176; $15 ; 26]$. Наиболее ранние материалы, датирующиеся не ранее середины VIII в., представлены грунтовыми могилами, часто с перекрытием из поперечных можжевеловых плах, либо погребальными сооружениями, представлявшими собой деревянный ящик без дна, так же перекрытый деревянными плахами. Одноярусные, парные и двухъярусные могилы уникальны: костяки расположены в вытянутом положении на спине. Такой обряд погребения находит полные аналогии в традиции захоронений тюркоязычного населения Подонья, Приазовья, Поволжья, Добруджи и не имеет ничего общего с византийским. Однако уже в середине VIII в. начинается христианизация местного населения. Наиболее ярко она проявилась в городах, прежде всего в Сугдее и на Боспоре. Как показывают исследования некрополя Судак-VI, датируемого серединой VIII - первой половиной IX в., плитовые христианские могилы, в основном детей, располагались вперемешку с грунтовыми и составляли не более $10 \%$ [15, с. 152-182]. Ситуация на сельских поселениях выглядела иначе. Например, так называемый Западный некрополь городища на плато Тепсень, существовавший до середины IX в., практически не имеет никаких христианских черт. Зато существует синхронный прихрамовый некрополь с плитовыми христианскими захоронениями [13, c. 119-176]. Антропологический тип погребенных на обоих некрополях примерно одинаковый. Среди захоронений некрополя поселения Кордон-Оба второй половины IX - первой половины $\mathrm{X}$ в. процент христианских могил примерно такой же, как и на некрополе Судак-VI, который возник более чем на сто лет раньше. Это притом, что на поселении был возведен христианский храм, сложенный техникой кладки «в елку». Таким образом, процесс восприятия христианской религии, неизбежный в связи с близостью Византийской империи, был сложным и растянутым во времени - от пол- 


\section{ВИЗАНТИЙСКАЯ ТАВРИКА}

ного принятия новой веры и сооружения плитовой могилы до частичного использования различных элементов христианского погребального сооружения и погребального инвентаря. Как показывают многолетние исследования, примерно к середине IX в. большая часть населения Юго-Восточного Крыма принимает христианство.

К этому времени относится и строительство основной массы христианских храмов либо капитальная перестройка храмов второй половины VIII - первой половины IX в., как, например, храмовый комплекс городища на плато Тепсень [13, с. 250-274]. Однако все эти процессы христианизации сосуществовали с языческими пережитками. Общеизвестен факт, что большинство культовых христианских сооружений возводится так же с использованием элементов кладки «в елку». В этом русле следует рассматривать и существование в качестве погребальной посуды, за редчайшим исключением, ойнахой баклинского типа. Этот наиболее оптимальный сосуд, появившийся и широко применявшийся у местного населения вследствие византинизации быта, не следует рассматривать как нечто особенное, связанное с изменениями в области идеологии. Не будем забывать, что подобные ойнахойи составляли значительный процент погребальных сосудов и у алано-готского населения южного берега Крыма [8].

Несомненным свидетельством христианизации являются и литургические предметы, количество которых благодаря раскопкам последних лет увеличивается [19, с. 320-329].

Таким образом, к середине IX в. христианский погребальный обряд и храмовое строительство сближают салтово-маяцкую культуру Крыма с провинциально-византийскими культурами других провинций империи. Вместе с тем уникальный религиозный синкретизм, подтверждения которому в связи с раскопками последних лет только увеличиваются, придает своеобразие мировоззрению крымских салтовцев.

Материальная культура населения ЮгоВосточной Таврики второй половины VII первой половины $\mathrm{X}$ в. целенаправленно изучается более 40 лет [1; 3, с. 69-104; 28]. К настоящему времени накоплен значительный и неплохо опубликованный материал. Целесооб- разно и в нем выделить византийские черты, проследить возможные корни и причины их появления и выяснить, стоят ли за ними какиелибо этнические изменения.

Рассмотрим керамический комплекс. Практически 100 \% амфорной тары - сосуды местного производства, которые в целом можно разделить на два основных типа: амфоры причерноморского типа и причерноморские амфоры с зональным рифлением или без него. Поскольку гончарных центров по их производству в Таврике, в том числе и Юго-Восточной, было несколько десятков [25], существует большое количество вариантов изделий. Все они неоднократно анализировались в литературе [24]. Отметим только, что время их появления приходится на первую половину VIII в. и до середины IX в. преобладают причерноморские амфоры с зональным рифлением, а затем в керамических комплексах постепенно увеличивается процент амфор причерноморского типа. Они преобладают в первой половине $\mathrm{X}$ в. и резко выходят из употребления к середине X в., что было связано с прекращением функционирования гончарных центров. В дальнейшем их производство никогда не возобновлялось. Эти амфоры в общих чертах повторяют византийские амфоры второй половины VII - первой половины X в., однако местное их производство не вызывает сомнений. Этнос гончаров установить сложно, но на некоторых изделиях, помимо греческих букв и христианских символов, встречены прочерченные по сырой глине граффити в виде тамгообразных знаков. Появление среди тарной керамики небольшого процента так называемых высокогорлых кувшинов связано с началом экономических связей с территорией Таманского полуострова. Время появления кувшинов традиционно определяется как середина - вторая половина IX в., хотя аргументов в пользу этого далеко не достаточно.

Кухонная керамика - визитная карточка керамического комплекса населения ЮгоВосточного Крыма второй половины VII - первой половины $\mathrm{X}$ века. Вероятнее всего, в основе ее лежит лепная и подправленная на гончарном круге кухонная керамика рубежа VIIVIII вв. - первой половины VIII века. Во всяком случае, эволюционное развитие и совер- 
шенствование основных гончарных операций прослеживается на основании следов, оставленных на сосудах [13, с. 196-205; 18; 20]. Главное отличие данной посуды от экземпляров Подонья и Приазовья заключается в более совершенной технике производства и, соответственно, в связи с ремесленным характером производства, в более стандартизированном и упрощенном линейно-волнистом орнаменте. Это и есть черты византинизации кухонной посуды, являющиеся результатом влияния более передовых византийских гончарных традиций, частично заимствованных местными ремесленниками, не отказавшимися от традиционных форм. Бесплодной, на мой взгляд, является дискуссия о том, что в городах, особенно на Боспоре, появляется другая кухонная посуда, отличная от экземпляров, обнаруженных в Сугдее и на остальных памятниках ЮгоВосточного Крыма и Керченского полуострова $[7 ; 22 ; 23]$. Разнообразие вариантов рассматриваемой посуды очень большое [31], но все это изделия одного этнического круга. Византинизация керамического комплекса выразилась и в появлении уже упоминавшихся так называемых ойнахой Баклинского типа, почти полностью заменивших традиционную лощеную посуду. Как известно, производились они на месте и обжигались в одних печах с причерноморскими амфорами. Налицо их генетическая связь с классическими ойнахойями и вместе с тем специфические местные особенности, единые для всей Таврики.

Единственным, несомненно византийским элементом керамического комплекса является поливная белоглиняная посуда [12]. Ее процент на рассматриваемой территории крайне незначителен - не более 2-3 \% в составе керамического комплекса. Подобная ситуация характерна и для Таманского полуострова. Единственным памятником Таврики, где поливная столовая посуда составляет больший процент, является Херсонес. Появление ее в Юго-Восточном Крыму - следствие торговых контактов с империей, и не более. Другое дело, что дата ее проникновения на полуостров, традиционно определяемая как середина - вторая половина IX в., нуждается в дальнейших обоснованиях.

Набор сельскохозяйственных орудий труда и предметов быта не является этническим показателем и свидетельствует о преимущественно земледельческом характере хозяйства населения, давно и полностью перешедшего к оседлости. Предметы вооружения и конского снаряжения, интернациональные по своей сути, тем не менее показывают несомненную связь с синхронными памятниками Подонья, и в первую очередь с кремационными некрополями [16;28].

Набор предметов этнографического костюма и украшений имеет некоторые специфические особенности, связанные с хорошо развитым местным ювелирным производством. По своей же сути он, естественно, интернационален и ориентирован на влияние моды, законодателями и «удовлетворителями» потребностей которой был Константинополь.

Результаты. Таким образом, салтовомаяцкая культура Крыма VIII - первой половины Х в. полностью соответствует современным критериям самостоятельной археологической культуры. Этнически она, несмотря на выдвигаемые концепции [2], однородна как для юго-восточной, так и для северо- и югозападной частей полуострова [21] и была оставлена местным оседлым населением, скорее всего праболгарскими племенами, на протяжении всего периода непосредственно соприкасавшимся с культурой Константинополя и центральных провинций Византийской империи. Эта прочная, достаточно привлекательная и модная византийская вуаль, накрывшая не только средневековую Таврику, завуалировала этническую суть самого населения ЮгоВосточного Крыма. Причем завуалировала не только для некоторых современных исследователей, но, вероятно, и для самих средневековых жителей, принявших христианство и считавших себя, таким образом, тоже византийцами. В этом плане культуру Юго-Восточного Крыма можно считать одним из вариантов провинциально-византийской. Однако в этом случае культура Херсонеса и памятников южного берега Крыма - другой, «более византинизированный» вариант провинциально-византийской культуры. Вместе с тем следует согласиться, что археологический термин «крымский вариант салтово-маяцкой культуры» нуждается в корректировке.

Изложенные выше соображения, основанные на современных археологических реали- 
ях, не могут ни подтвердить, ни опровергнуть выводы о политическом подчинении данной территории полуострова в рассматриваемый хронологический период. Пролить свет могут другие источники. Письменные источники хорошо известны как своей малочисленностью, так и изначальной субъективностью, а тем более субъективностью их современной интерпретации. Другое дело - эпиграфические, нумизматические и сфрагистические. Однако первых двух пока единицы [9], а за третьими, только при учете накопления материала, возможно в будущем и решение вопроса.

\section{СПИСОК СОКРАЩЕНИЙ}

БСП-Българите в Северното Причерноморие. ДБ-Древности Боспора. Д3 - Дриновський збірник. $C C-$ Сугдейский сборник. ТГЭ - Труды Государственного Эрмитажа. $T C$ - Таврические студии. $X A-$ Хазарский альманах.

\section{СПИСОК ЛИТЕРАТУРЫ}

1. Айбабин, А. И. Этническая история ранневизантийского Крыма / А. И. Айбабин. - Симферополь : Дар, 1999. - 352 с.

2. Баранов, В. И. К вопросу об этнокультурной дифференциации салтово-маяцких памятников Крыма (VII-X вв.) / В. И. Баранов // Причерноморье, Крым, Русь в истории и культуре : материалы III Судакской Междунар. науч. конф. - Киев ; Судак : Академпериодика, 2006. - Т. II. - С. 34-36.

3. Баранов, И. А. Таврика в эпоху раннего Средневековья / И. А. Баранов. - Киев : Академпериодика, 1990.- $168 \mathrm{c}$.

4. Баранов, И. А. Болгаро-хазарский горизонт средневековой Сугдеи / И. А. Баранов // Проблеми на прабългарската история и култура. - София : БАН, 1991. - С. 145-159.

5. Баранов, И. А. Пастирско-пенковската култура и проблемът за разселването на прабългарските племена от Средното Поднепровие и Таврика / И. А. Баранов, В. В. Майко // БСП. - 1995. - Т. IV. C. 71-88.

6. Баранов, И. А. Праболгарские горизонты Судакского городища середины VIII - первой половины Х вв. / И. А. Баранов, В. В. Майко // БСП. 2000. - T. VII. - C. 83-100.

7. Бочаров, С. Г. Керамика хазарской эпохи в восточном Крыму / С. Г. Бочаров // Керамика ха- зарского каганата (VII-X вв.) и проблема идентификации болгарской керамики в странах Причерноморья и Поволжье : тез. Междунар. науч. семинара. - Симферополь : [б. и.], 2011. - С. 13-19.

8. Веймарн, Е. В. Скалистинский могильник / Е. В. Веймарн, А. И. Айбабин. - Киев : Наукова думка, 1993. - 204 с.

9. Виноградов, А. Ю. Институт тудуна и хазары в юго-западном Крыму VIII - начала IX вв. в контексте новых данных эпиграфики / А. Ю. Виноградов, А. В. Комар // СС. - 2005. - Вып. II. - С. 38-56.

10. Джанов, А. В. Сугдея в III-VII вв. / А. В. Джанов // СС. - 2004. - Вып. I. - С. 45-74.

11. Житие Стефана Сурожского в контексте истории Крыма иконоборческого времени / Ю. М. Могаричев [и др.]. - Симферополь : Антиква, 2009. - 334 с.

12. Майко, В. В. Поливная керамика второй половины IX - первой половины Х вв. из Сугдеи / В. В. Майко // Историко культурные связи Причерноморья и Средиземноморья X-XVIII вв. По материалам поливной керамики. - Симферополь : [б. и.], 1998. - С. 138-140.

13. Майко, В. В. Средневековое городище на плато Тепсень в юго-восточном Крыму / В. В. Майко. - Киев : Академпериодика, 2004. - 316 с.

14. Майко, В. В. К вопросу о рунических и тамгообразных знаках тюрко-болгар Таврики VIII-X вв. / В. В. Майко // ХА. - 2005. - Т. 4. - С. 234-244.

15. Майко, В. В. Средневековые некрополи Судакской долины / В. В. Майко. - Киев : Академпериодика, 2007. - 273 с.

16. Майко, В. В. Комплекс оружия, конского снаряжения и бытовых предметов с праболгарского поселения IX - первой половины X вв. в юговосточном Крыму / В. В. Майко, А. В. Гаврилов, В. Д. Гукин // ХА. - 2009. - Т. 8. - С. 237-263.

17. Майко, В. В. Юго-Восточный Крым VIIIXI вв. Два примера провинциально-византийской культуры / В. В. Майко // ТГЭ. - 2010. - Т. 51. С. $428-437$.

18. Майко, В.В.Праболгарские памятники юговосточного Крыма. Эволюция керамического комплекса / В. В. Майко // Д3. - 2012. - Т. V. - С. 79-93.

19. Майко, В. В. Раннесредневековые материалы городища «Белинское» в Восточном Крыму / В. В. Майко, В. Г. Зубарев, С. В. Ярцев // ДБ. 2016. - T. 20. - C. 320-329.

20. Майко, В. В. Салтово-маяцкая кухонная керамика восточного Крыма. Исследователи и исследования / В. В. Майко // Боспорские чтения. Керчь : Изд-во КФУ, 2016. - Вып. XVII : Боспор Киммерийский и варварский мир в период античности и средневековья. Исследователи и исследования. С. 256-261.

21. Майко, В. В. Северо-западный Крым в VIIXV вв. Попытка исторического очерка / В. В. Май- 
ко // Археология Северо-Западного Крыма : материалы III Междунар. науч.-практ. конф. - Симферополь : Наследие тысячелетий, 2017. - С. 118-128.

22. Науменко, В. Е. Боспор в системе византийско-хазарских отношений / В. Е. Науменко // Боспорские чтения. - Керчь : Керч. гор. тип., 2000. Вып. I : Боспор Киммерийский на перекрестье греческого и варварского миров. - С. 96-105.

23. Науменко, В. Е. Место Боспора в системе византийско-хазарских отношений / В. Е. Науменко // Бахчисарайский историко-археологический сборник. - Симферополь : Таврия-Плюс, 2001. - Вып. 2. C. 336-361.

24. Науменко, В. Е. Пифосы, высокогорлые кувшины, амфоры, столовая керамика / В. Е. Науменко // Тиритака. Раскоп XXVI : Археологические комплексы VIII-Х вв. / В. Н. Зинко, Л. Ю. Пономарев. - Симферополь ; Керчь : АДЕФ-Украина, 2009. - C. 32-64.

25. Паршина, Е. А. Гончарные центры Таврики VIII-X вв. / Е. А. Паршина, И. Б. Тесленко, С. М. Зеленко // Морська торгівля в Північному Причорномор'ї. - Киев : Изд-во Київ. нац. ун-та, 2001. - С. 52-81.

26. Пономарев, Л. Ю. О некоторых погребальных обрядах населения Керченского полуострова в VIII-IX вв. / Л. Ю. Пономарев // Боспорские чтения. - Керчь : ЦАИ Деметра, 2001. - Вып. II : Боспор Киммерийский и Понт в период античности и средневековья. - С. 116-121.

27. Пономарев, Л. Ю. Жилища восточного Крыма эпохи хазарского каганата (по материалам раскопок салтово-маяцких поселений Керченского полуострова) / Л. Ю. Пономарев // СС. - 2012. T. V. -C. 186-209.

28. Пономарев, Л. Ю. Хозяйственная деятельность населения салтовской культуры Керченского полуострова (краткий обзор археологических источников) / Л. Ю. Пономарев // Салтовомаяцька археологічна культура : Проблеми та дослідження. - Харків : Вид. Савчук О.О. : ОКЗ «Харківський науково-методичний центр охорони культурної спадщини», 2012. - Вип. 2. - С. $67-$ 78 + ил. (С. 130-132).

29. Пономарев, Л. Ю. Двухкамерные жилища (дома-пятистенки) салтово-маяцких поселений Кер-

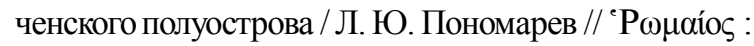
сб. ст. к 60-летию проф. С.Б. Сорочана. - Харьков : Майдан, 2013. - С. 440-461. - (Нартекс. Byzantina Ukrainensia; т. 2).

30. Пономарев, Л. Ю. Жилые однокамерные постройки салтово-маяцких поселений Керченского полуострова / Л. Ю. Пономарев // ТС. - 2014. Т. 6. - С. 131-139.

31. Пономарев, Л. Ю. Салтово-маяцкие горшки из поселений Керченского полуострова
/ Л. Ю. Пономарев // Степи Европы в эпоху средневековья. - 2014. - Т. 12. - С. 239-276.

32. Сорочан, С. Б. О положении и статусе Сугдеи в VI-IX вв. / С. Б. Сорочан // Древности 20062008. - Харьков : МД, 2008.- С. 108-124.

33. Флеров, В. С. «Города» и «замки» Хазарского каганата. Археологическая реальность / В. С. Флеров. - М. : Мосты культуры, 2010. - 260 с.

\section{REFERENCES}

1. Aybabin A.I. Etnicheskaya istoriya rannevizantiyskogo Kryma [Ethnic History of the Early Byzantine Crimea]. Simferopol, Dar Publ., 1999. 352 p. (in Russian).

2. Baranov V.I. K voprosu ob etnokulturnoy differentsiatsii saltovo-mayatskikh pamyatnikov Kryma (VII-X vv.) [To the Question of Ethnocultural Differentiation of Saltovo-Mayaki Monuments of the Crimea (the $7^{\text {th }}-10^{\text {th }}$ Centuries)]. Prichernomorye, Krym, Rus v istorii i kulture. Materialy III Sudakskoy Mezhdunarodnoy nauchnoy konferentsii [Black Sea Coast, Crimea, Russia in the History and Culture. Materials of the $3^{\text {rd }}$ Sudak International Scientific Conference]. Kiev; Sudak, Akademperiodika Publ., 2006, vol. 2, pp. 34-36. (in Russian).

3. Baranov I.A. Tavrika v ehpohu rannego srednevekovya [Taurika in the Early Middle Ages]. Kiev, Akademperiodika Publ., 1990. 168 p. (in Russian).

4. Baranov I.A. Bolgaro-khazarskiy gorizont srednevekovoy Sugdei [The Bolgaro-Hazar Horizon of Medieval Sugdeja]. Problemy na prabalgarskata istoriya i kultura [Problems of the Prabolgar History and Culture]. Sofia, BAN Publ., 1991, pp. 145-159. (in Russian).

5. Baranov I.A., Mayko V.V. PastirskoPenkovskata Culture and the Problem of Resettlement of Prabolgar Tribes of the Central Dnieper Bank and Taurica. Balgarite v Severnoto Prichernomorie [Bulgarians in Northern Black Sea Coast], 1995, vol. IV, pp. 71-88. (in Russian).

6. Baranov I.A., Mayko V.V. Prabolgarskie gorizonty Sudakskogo gorodishcha serediny VIIIpervoy poloviny X vv. [The Prabolgar Horizons of the Sudak Ancient Settlement of the mid $8^{\text {th }}$ - the first half of the $10^{\text {th }}$ Centuries]. Balgarite $v$ Severnoto Prichernomorie [Bulgarians in the Northern Black Sea Coast], 2000, vol. VII, pp. 83-100. (in Russian).

7. Bocharov S.G., Koval V.Yu. Keramika khazarskoy epokhi v vostochnom Krymu [Ceramics of the Hazaria Era in East Crimea]. Mezhdunarodnyy nauchnyy seminar "Keramika khazarskogo kaganata (VII-X vv.) i problema identifikatsii bolgarskoy keramiki $v$ stranakh Prichernomorya $i$ Povolzhye»: tezisy [International Scientific Seminar on 
Ceramics of Khazar Khanate (the $7^{\text {th }}-10^{\text {th }}$ centuries) and the Problem of Identification of the Bulgarian Ceramics in the Countries of Black Sea Coast and Volga region: Theses]. Simferopol, 2011, pp. 13-19. (in Russian).

8. Veymarn E.V., Aybabin A.I. Skalistinskiy mogilnik [Skalistinsky Burial Ground]. Kiev, Naukova dumka Publ., 1993. 204 p. (in Russian).

9. Vinogradov A.Yu., Komar A.V. Institut tuduna i khazary v yugo-zapadnom Krymu VIII-nachala IX vv. v kontekste novykh dannykh epigrafiki [Institute of Tudun and Hazars in the Southwest Crimea $8^{\text {th }}-$ the early $9^{\text {th }}$ Centuries in the Context of New Epigraphic Data]. Sugdeyskiy sbornik [Sugdeian Collection], vol. II, pp. 38-56. (in Russian).

10. Dzhanov A.V. Sugdeya v III-VII vv. [Sugdeja in the $3^{\text {th }}-7^{\text {th }}$ Centuries]. Sugdeyskiy sbornik [Sugdeian Collection], 2004, vol. I, pp. 45-74. (in Russian).

11. Mogarichev Yu.M., et al. Zhitie Stefana Surozhskogo $v$ kontekste istorii Kryma ikonoborcheskogo vremeni [Stefan Surozhsky's Life in the Context of History of the Crimea of Iconoclastic Time]. Simferopol, AntikvA Publ., 2009. 334 p. (in Russian).

12. Mayko V.V. Polivnaya keramika vtoroy poloviny IX - pervoy poloviny X vv. iz Sugdei [Glazed Ceramics of the Second Half of the $9^{\text {th }}-$ First Half of the $10^{\text {th }}$ Centuries from Sugdeja]. Istoriko-kulturnye svyazi Prichernomorya i Sredizemnomorya $V_{-}$ XVIII vv. po materialam polivnoy keramiki [Historical and Cultural Connections of the Black Sea Coast and the Mediterranean Region of the $10^{\text {th }}-18^{\text {th }}$ Centuries. Based on Materials of Glazed Ceramics]. Simferopol, 1998, pp. 138-140. (in Russian).

13. Mayko V.V. Srednevekovoe gorodishche na plato Tepsen $v$ yugo-vostochnom Krymu [The Medieval Settlement on the Plateau Tepsen in the Southeast Crimea]. Kiev, Akademperiodika Publ., 2004. 316 p. (in Russian).

14. Mayko V.V. K voprosu o runicheskikh i tamgoobraznykh znakakh tyurko-bolgar Tavriki VIIIX vv. [On the Runic and Tamga-Shaped Signs of TurkBulgarians of Taurika in the $8^{\text {th }}-10^{\text {th }}$ Centuries]. Khazarskiy almanakh [Hazaria Almanac], 2005, vol. 4, pp. 234-244. (in Russian).

15. Mayko V.V. Srednevekovye nekropoli Sudakskoy doliny [Medieval Necropolises of the Sudak Valley]. Kiev, Akademperiodika Publ., 2007. 273 p. (in Russian).

16. Mayko V.V., Gavrilov A.V., Gukin V.D. Kompleks oruzhiya, konskogo snaryazheniya i bytovykh predmetov s prabolgarskogo poseleniya IXpervoy poloviny $\mathrm{X}$ vv. v yugo-vostochnom Krymu [Complex of Weapons, Horse Equipment and Household Objects from the Prabolgar Settlement of the $9^{\text {th }}$ - first half of the $10^{\text {th }}$ Centuries in the Southeast Crimea]. Khazarskiy almanakh [Hazaria Almanac], 2009, vol. 8, pp. 237-263. (in Russian).

17. Mayko V.V. Yugo-Vostochnyy Krym VIII-XI vv. Dva primera provintsialno-vizantiyskoy kultury[Southeast Crimea of the $8^{\text {th }}-11^{\text {th }}$ Centuries. Two Examples of the Provincial-Byzantine Culture]. Trudy Gosudarstvennogo Ermitazha. T. 51. Vizantiya v kontekste mirovoy kultury [Works of the State Hermitage. Vol. 51. Byzantium in the Context of World Culture], 2010, pp. 428-437. (in Russian).

18. Mayko V.V. Prabolgarskie pamyatniki yugovostochnogo Kryma. Evolyutsiya keramicheskogo kompleksa [Prabolgar Monuments of the Southeast Crimea. Evolution of a Ceramic Complex]. Drinovskiy sbornik [Drinovsky Collection], 2012, vol. V, pp. 7993. (in Russian).

19. Mayko V.V., Zubarev V.G., Yartsev S.V. Rannesrednevekovye materialy gorodishcha "Belinskoe" v Vostochnom Krymu [Early Medieval Materials of the Ancient Settlement Belinskoe in East Crimea]. Drevnosti Bospora [Bospor's Antiquities], 2016, vol. 20, pp. 320-329. (in Russian).

20. Mayko V.V. Saltovo-mayatskaya kukhonnaya keramika vostochnogo Kryma. Issledovateli i issledovaniya [Saltovo-Mayaki Kitchen Ceramics of East Crimea. Researchers and Research]. Bosporskie chteniya. Vyp. XVII: Bospor Kimmeriyskiy $i$ varvarskiy mir $v$ period antichnosti i srednevekovya. Issledovateli i issledovaniya [Bosporan Readings. Vol. XVII: Bospor Kimmeriysky and the Barbaric World in the Period of Antiquity and the Middle Ages. Researchers and Research]. Kerch, Izd-vo KFU, 2016, pp. 256-261. (in Russian).

21. Mayko V.V. Severo-zapadnyy Krym v VIIXV vv. Popytka istoricheskogo ocherka [The Northwest Crimea in the $7^{\text {th }}-15^{\text {th }}$ Centuries. Attempt of a Historical Sketch]. Arkheologiya Severo-Zapadnogo Kryma. Materialy III Mezhdunarodnoy nauchnoprakticheskoy konferentsii [Archaeology of the Northwest Crimea. Materials of the $3^{\text {rd }}$ International Scientific and Practical Conference]. Simferopol, Nasledie tysyacheletiy Publ., 2017, pp. 118-128. (in Russian).

22. Naumenko V.E. Bospor v sisteme vizantiyskokhazarskikh otnosheniy [Bospor in the System of the Byzantine-Hazaria Relations]. Bosporskie chteniya. Vyp. I: Bospor Kimmeriyskiy na perekreste grecheskogo $i$ varvarskogo mirov [Bosporan Readings. Vol. I: Bospor Kimmeriysky on the Crossing of the Greek and Barbaric Worlds]. Kerch, Kerchenskaya gorodskaya tipografiya Publ., 2000, pp. 96-105. (in Russian).

23. Naumenko V.E. Mesto Bospora v sisteme vizantiysko-khazarskikh otnosheniy [Bospor's Place in the System of the Byzantine-Hazaria Relations]. Bahchisarayskiy istoriko-arkheologicheskiy sbornik 
[Bakhchisarai Historical and Archaeological Collection]. Simferopol, Tavriya-Plus Publ., 2001, vol. 2, pp. 336-361. (in Russian).

24. Naumenko V.E. Pifosy, vyisokogorlye kuvshiny, amfory, stolovaya keramika [Pithoses, HighNeck Jugs, Amphoras, Table Ceramics]. Zinko V.N., Ponomarev L.Yu. Tiritaka. Raskop XXVI. Arkheologicheskie kompleksy VIII-X vv. [Tiritaka. Excavation XXVI. Archaeological Complexes of the $8^{\text {th }}-10^{\text {th }}$ Centuries]. Simferopol; Kerch, ADEF-Ukraina Publ., 2009, pp. 32-64. (in Russian).

25. Parshina E.A., Teslenko I.B., Zelenko S.M. Goncharnye tsentry Tavriki VIII-X vv. [Potter's Centers of Taurika of the $8^{\text {th }}-10^{\text {th }}$ Centuries]. Morska torgivlia $v$ Pivnichnomu Prichornomori [Sea Trade in the Northern Black Sea Coast]. Kiev, Kiivskyi natsionalnyi universitet im. Tarasa Shevchenka Publ., 2001, pp. 5281. (in Russian).

26. Ponomarev L.Yu. O nekotorykh pogrebalnykh obryadakh naseleniya Kerchenskogo poluostrova $\mathrm{v}$ VIII-IX vv. [About Some Funeral Ceremonies of the Population of the Kerch Peninsula in the $8^{\text {th }}-9^{\text {th }}$ Centuries]. Bosporskie chteniya. Vyp. II. Bospor Kimmeriyskiy $i$ Pont $v$ period antichnosti $i$ srednevekovya [Bospor Kimmeriysky and Pontus in the Period of Antiquity and the Middle Ages]. Kerch, TsAI Demetra Publ., 2001, pp. 116-121. (in Russian).

27. Ponomarev L.Yu. Zhilishcha vostochnogo Kryma epokhi khazarskogo kaganata (po materialam raskopok saltovo-mayatskikh poseleniy Kerchenskogo poluostrova) [Dwellings of East Crimea of the Khazar Khanate Era (Based on Materials of Excavation of Saltovo-Mayaki Settlements of the Kerch Peninsula)]. Sugdeyskiy sbornik [Sugdeian Collection], 2012, vol. V, pp. 186-209. (in Russian).

28. Ponomarev L. Yu. Khozyaystvennaya deyatelnost naseleniya saltovskoy kultury Kerchens-kogo poluostrova (kratkiy obzor arkheologicheskikh istochnikov) [Economic Activity of the Population of Saltovo-Mayaki Culture of the Kerch Peninsula (Short Review of Archaeological Sources)]. Saltovo-mayatska arkheologichna kultura: Problemi ta doslidzhennia [Saltovo-Mayaki Archaeological Culture: Problems and Research]. Kharkiv, Savchuk O.O. Publ., 2012, vol. 2, pp. 67-78, 130-132. (in Russian).

29. Ponomarev L. Yu. Dvukhkamernye zhilishcha (doma-pyatistenki) saltovo-mayatskikh poseleniy Kerchenskogo poluostrova [Two-Chamber Dwellings (Five-Wall Houses) of Saltovo-Mayaki Settlements of the Kerch Peninsula]. Romaios. Vol. 2. Sbornik statey k 60-letiyu prof. S.B. Sorochana. Narteks. Byzantine Ukrainensis [Roman. Vol. 2. The Collection of Articles to the $60^{\text {th }}$ Birth Anniversary of Prof. S.B. Sorochan]. Kharkiv, Maydan Publ., 2013, pp. 440-461. (Narteks. Byzantina Ukrainensia; vol. 2). (in Russian).

30. Ponomarev L.Yu. Zhilye odnokamernye postroyki saltovo-mayatskikh poseleniy Kerchenskogo poluostrova [Inhabited Single-Chamber Constructions of Saltovo-Mayaki Settlements of the Kerch Peninsula]. Tavricheskie studii [Taurian Studies], 2014, vol. 6, pp. 131-139. (in Russian).

31. Ponomarev L. Yu. Saltovo-mayatskie gorshki iz poseleniy Kerchenskogo poluostrova [SaltovoMayaki Pots from Settlements of the Kerch Peninsula]. Stepi Evropy v epokhu srednevekovya [Steppes of Europe in the Middle Ages ], 2014, vol. 12, pp. 239276. (in Russian).

32. Sorochan S.B. O polozhenii i statuse Sugdey v VI-IX vv. [About Condition and Status of Sugdeja in the $6^{\text {th }}-9^{\text {th }}$ Centuries]. Drevnosti 2006-2008 [Antiquities 2006-2008]. Kharkiv, MD Publ., 2008, pp. 108-124. (in Russian).

33. Flerov V.S. «Goroda» $i$ «zamki» Khazarskogo kaganata. Arkheologicheskaya realnost ["Cities" and "Castles" of Khazar Khanate. Archaeological Reality]. Moscow, Mosty kultury Publ., 2010. 260 p. (in Russian).

\section{Information about the Author}

Vadim V. Maiko, Doctor of Sciences (History), Director, Institute of Archaeology of Crimea, RAS, Prosp. Vernadskogo, 2, 295007 Simferopol, Russian Federation, vadimmaiko1966@mail.ru, https://orcid.org/0000-0003-1065-4836

\section{Информация об авторе}

Вадим Владиславович Майко, доктор исторических наук, директор, Институт археологии Крыма РАН, просп. Акад. Вернадского, 2, 295007 г. Симферополь, Российская Федерация, vadimmaiko1966@mail.ru, https://orcid.org/0000-0003-1065-4836 